\title{
Cooperative Learning Strategy with a Mobile Environment
}

\author{
Kil Hong Joo ${ }^{1}$ and Nam Hun Park ${ }^{2 *}$ \\ 1 \\ Dept. Of Computer Education, Gyeongin National University of Education, San \\ 6-8 Seoksudong Manangu Anyangsi, Gyeonggi, Korea, 430-040 \\ ${ }^{2}$ Dept. Of Computer Science, Anyang University, 102 Samsungli, Buleunmyun, \\ Ganghwagun, Incheon, Korea, 417-833 \\ khjoo@ginue.ac.kr,nmhnpark@anyang.ac.kr
}

\begin{abstract}
Cooperative learning is one of main methods to achieve the educational goal of problem-solving and decision-making ability improvement. In line with the changing learning environment, offline cooperative learning has evolved to a web-based cooperative learning these days. However, in order to improve the educational use of the basic ideas of web-participation, sharing and openness, wireless network environment is indispensable. In this point of view, web-based cooperative learning strategies are designed under the wireless network environment and applied to verify their validity and effectiveness in line with educational needs. Also, in this study, how to utilize web-based online learning assistance system (WLS) was presented and teachers' role model was developed for enhanced cooperative learning effectiveness.
\end{abstract}

Keywords: Web-based Learning, Cooperative Strategy, Multi-Culture

\section{Introduction}

Of many educational goals, problem-solving ability and decision-making ability improvement is one of the most frequently-discussed subjects. To achieve these goals, numerous studies are going on. A good example is those on cooperative learning.

Cooperative learning practice offline, however, is limited in terms of time, space and information usage, taking longer time to produce a result. For these reasons, offline cooperative learning can be only limitedly utilized in actual classes. Web-based cooperative learning was developed to address such problems. Through web-based cooperative learning practices, learning environment was expanded to blur some temporal and spatial limitations; videos, voice materials and cutting-edge multi-media resources became available for study, which had been impossible with printing media before; and more dynamic and extensive information began to be exchanged quickly.

In the previous web-based learning environment, diverse encyclopedia-type of information was utilized. Such type of information is already made and fixed one which is not processible. So it can hardly reflect in learners' demand. In this context, the idea of web has garnered more attention lately. Web is the service generated in line with the spirit of our time represented as participation, share and openness. It is also the basic technology thereunder. Web refers to web as a platform oriented for users' experience based on participation and openness. Cooperative learning based on this web would be able to address the weaknesses of previous web-based cooperative learning while approaching closer to the essential goal of cooperative learning - improved problemsolving and decision-making ability.

Web-based cooperative learning, still, could be limited if performed only within classrooms or computer rooms because problem-solving ability is acquired in the process of resolving diverse daily issues. Thus, in order to maximize the educational effectiveness

\footnotetext{
* Corresponding author
} 
of the web paradigm, wireless network environment is all the more necessary. Classroom boundaries are blurred. Learners come to practice in diverse time and space. They should be allowed to collect, process, share information collected from corners of their school or during their days and then re-process and re-produce such data in real time.

In this understanding, the study seeks to examine strategies for the web-based cooperative learning in wireless network environment and compare its effectiveness with those of the extant cooperative learning method. For the purpose of this study, the following details and methods are dealt with herein;

First, units and materials appropriate for cooperative learning are selected from each subject. The selected materials are taught in three different ways - offline cooperative learning method, web-based cooperative learning and wireless network web-based cooperative learning. Then the students' interest, satisfaction and achievement are evaluated.

Second, for cooperative learning in a wireless network environment, every student is provided with $1 \mathrm{PC}$ and allowed to use web-based google documentation tool and naver blogs via the school's wireless network system.

\section{Related Works}

Recently the Korean Education and Research Information Service prototyped a future classroom called u-Class in a ubiquitous environment. Though there are multiple techniques to make it real, the key is RFID and wireless network technologies [1-2]. Given the fact that even the kind of information recognized via RFID also needs to be processed via wireless network in real time, the key between the two would be the wireless network technology.

Cooperative learning is a teaching-learning method where personal achievement is linked to the whole group members' achievement so heterogeneous members of a small group cooperate with each other to achieve a common goal and receive reward altogether [3]. This cooperative learning method helps learners absorb diverse viewpoints, expand their horizon of thinking, acquire the cognitive regulation technique for the acceptance of different opinions of others, and build the sense of responsibility for study so that learners become more self-directed in their learning process. It also helps further clarify one's own thought and improve learning motivation while working together with colleagues, inducing positive and active participation [4].

As a result of analyzing previous literature on the extant web-based cooperative learning, although the web-based learning does overcome the weaknesses of offline cooperative learning - temporal and spatial limitations, it still showed shortfalls in the aspect of interaction, a key area of cooperative learning. In this situation, more specific study is necessary on personal sense of responsibility and interpersonal skills $[5,6,7]$.

The concept of web is basically to expand user participation. Based on the idea of usercentered participation and sharing, web can function regardless of OS/browser and, if necessary, it can be expanded by users [8]. Cooperative learning based on this web enables interaction among learners-instructors-learners in a synchronized manner, encourages proactive participation of learners, provides diverse information quickly and function as a digital portfolio.

To sum the studies above, the web-based cooperative learning is a new web-based model addressing the shortcomings of the existing web-based cooperative learning method. But its effectiveness is limited under the present educational situation where sometimes too many students are in a single classroom or only wired network environment is provided. Such a situation is expected to be improved by the core technology in the future classroom, called wireless network. 


\section{Web-Based Cooperative Learning Strategies}

This research seeks to overcome the limitations of the extant web-based cooperative learning by introducing a wireless network environment. Accordingly, new cooperative learning strategies were designed herein. The proposed strategies are consisted of three steps of problem situation recognition and goal setting, problem solving and evaluation and reflection.

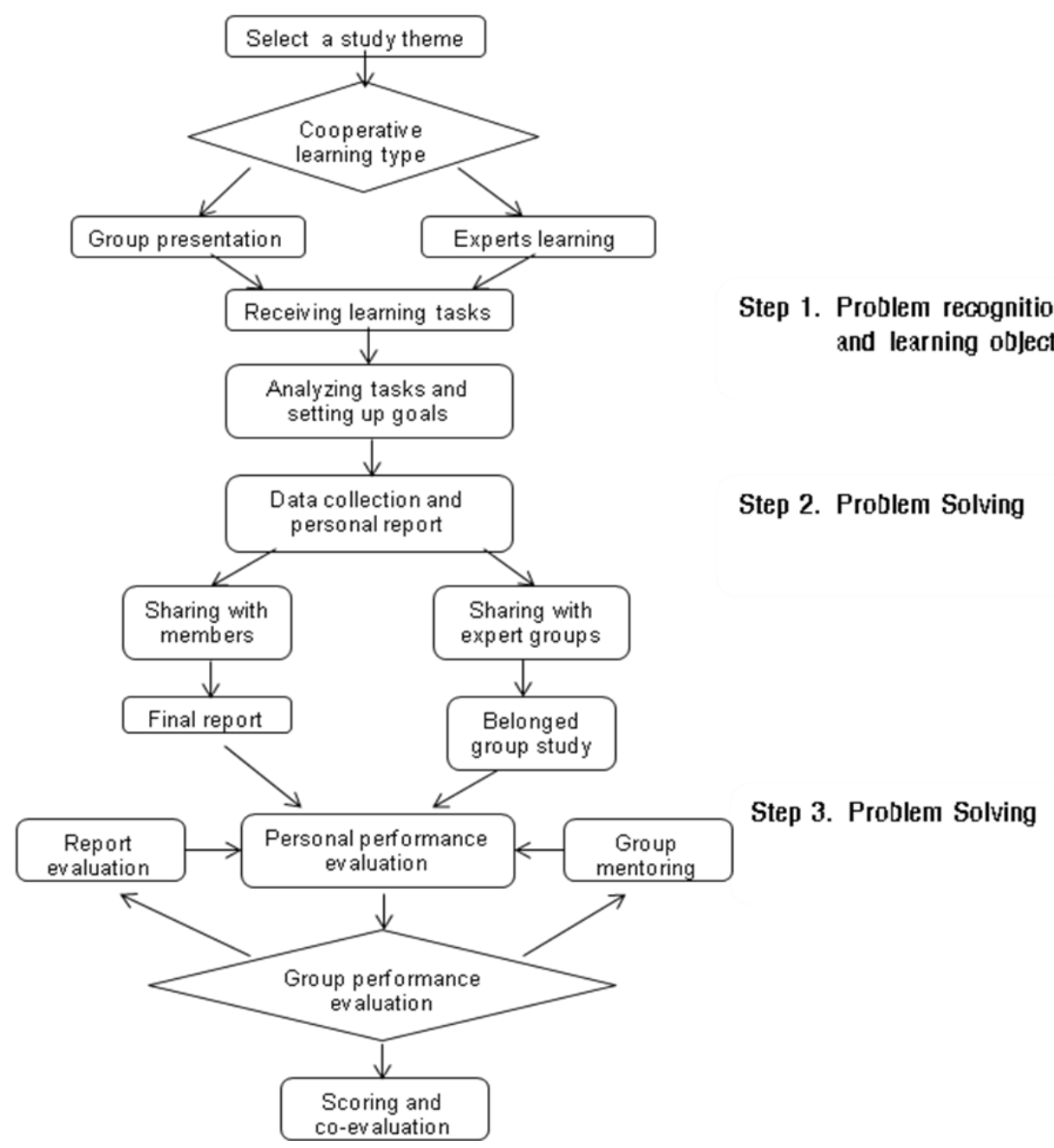

Figure 1. Web-Based Cooperative Learning Strategy

In the problem situation recognition and goal setting phase, students themselves check a study task in the class web blog, take a level test to find out where they are, and set goals through online/offline discussion. Teachers monitor the level test results and offer feedback to those failing to achieve a certain level so that such student can set an appropriate goal at their level. In this phase, the extant web-based cooperative learning did not offer the real-time discussion among the students for each of their own recognized issues. But in the strategy presented herein, individual students can discuss whatever problem they recognize in real time at the very place of such recognition. This mechanism reduces unnecessary time spending and offer say to even very passive students.

In the problem-solving stage, based on the goals set in the web discussion, individual tasks are shared and students move to their own necessary places to collect data and produce information. The produced information, depending upon the type of cooperative 
learning, is shared within the same group or with those performing the same task in other groups. By sharing data, students can modify and improve their own information, write the final group report, make a presentation and learn by broadly sharing with their original members.

Previously in the web-based cooperative learning, the data collection and process in this stage were separated in terms of time and space. But under this research strategy, data collection and process are integrated to shorten the time required for problem resolution while ensuring more time for learners to review own-established problem-solving strategy.

In the evaluation and reflection stage, students send individual test results to teachers and the teachers produce group-specific statistics. Based on the statistical analysis, excellent groups are rewarded and those failing to achieve a certain level are instructed to review their final group report, receive mentoring from the members of the same group and sent their re-test results. After completing all of the learning procedures, group-specific study outputs are shared in the class web blog and evaluated by one another.

\section{WLS (Web Based Learning System) Composition and Design}

WLS is a system to assist the web-based cooperative learning online. It monitors the progress of students during the cooperative learning process in real time to provide mentoring about study goal setting, problem solving and study achievement. The figure 2 below shows the overall structure of the WLS system.

The system is operated through the google document tool and naver blog and supports the following functions; first, it produces statistics based on the level test results and final test results to assess the levels of student performance and provides proper feedback. Students send their pre/post-intervention tests to teachers and teachers refer to studentspecific and test question-specific statistics to identify those with poor performance and let them receive teachers' and colleagues' mentoring.

Second, in the problem-solving stage, teachers monitor information production process and advice about the produced information to lead students' problem-solving efforts in the right direction. Students, in the information production process, receive real-time feedback from teachers through the 'sharing' function and 'share view' function in the google document tool.

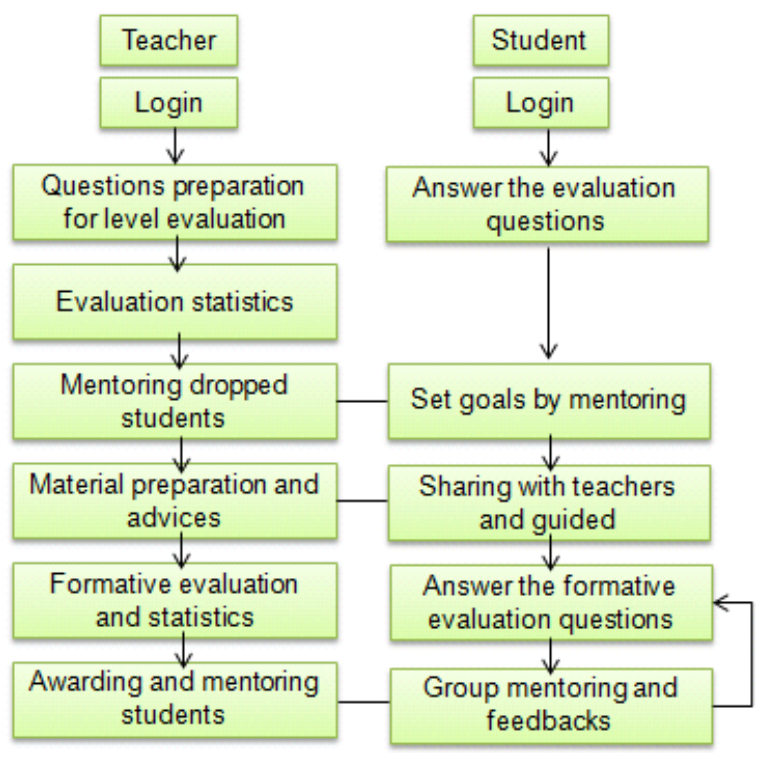

Figure 2. WLS Structure 


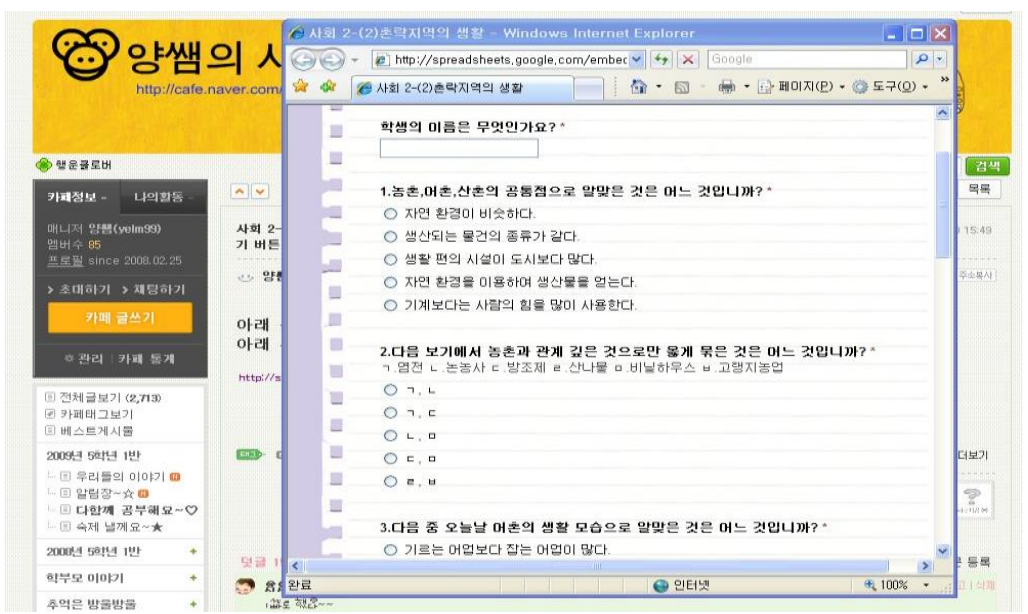

Figure 3. Final Test Screen Connected in a Link

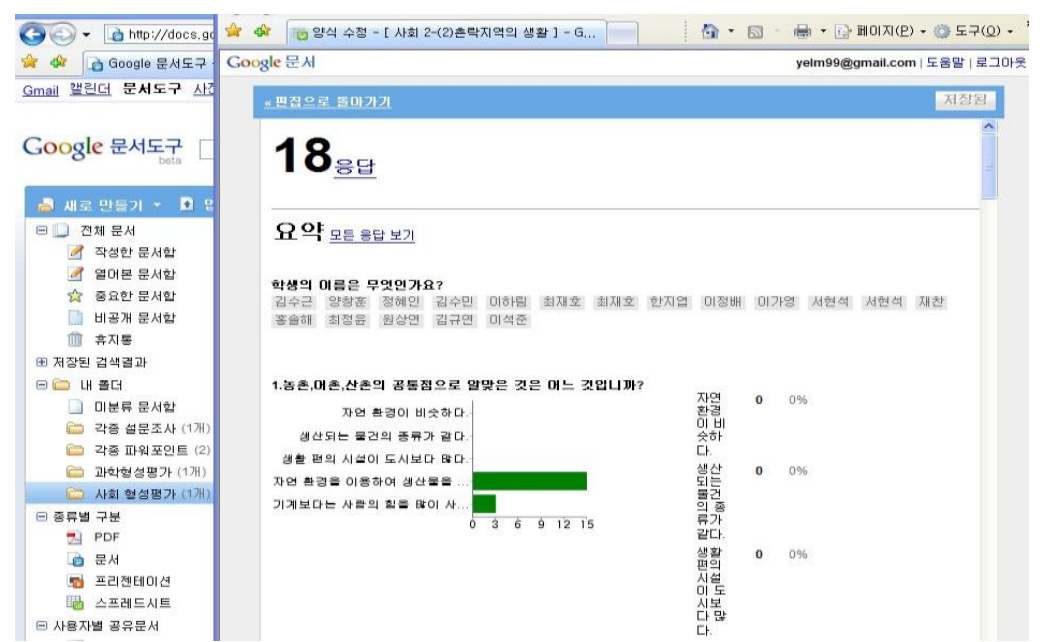

Figure 4. Screen for Final Test Question-Specific Statistics

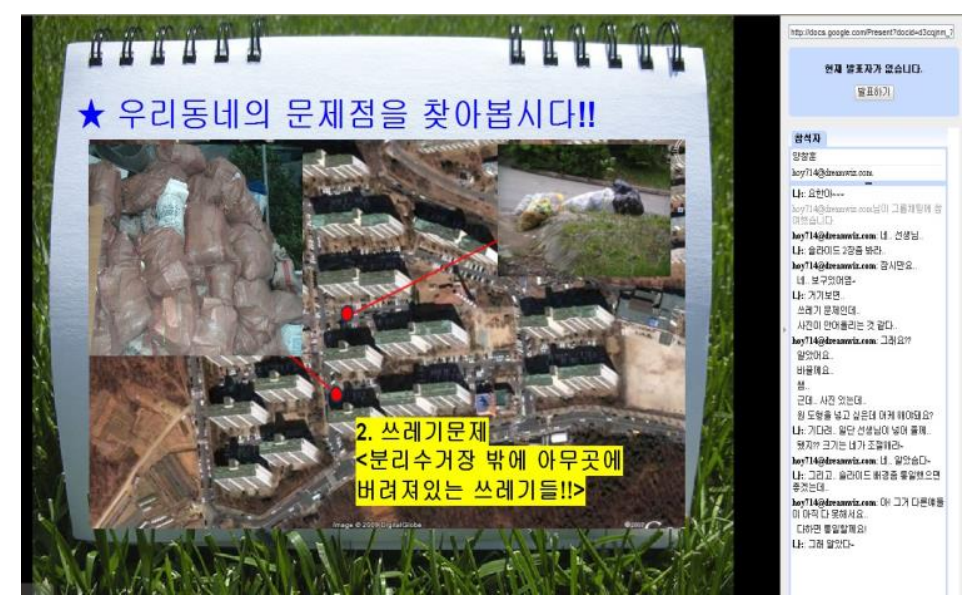

Figure 5. Presentation Feedback Screen 


\section{Experimental Results}

This study investigated $5^{\text {th }}$-grade elementary school curriculum by looking at one class. To this end, appropriate subjects and study themes were selected for cooperative learning and the instruction strategy suggested in this research. In doing so, the following selection criteria were applied; first, the contents should be suitable for group formation and individual task assignment for problem solving. Since the groups have 5 6 members, the contents should have at least 5 6 individual sub-themes to be assigned without overlap. Second, the contents should base on textbooks in resolving everyday issues. To take advantage of wireless network, it should involve diverse different space so that students use more than just simple online scraps but their own collected and produced contents. To achieve this, the contents are re-structured based on textbook details to present as common everyday issues. Third, in order to encourage learners to exercise comprehensive aspects of their ability such as knowledge, information, way of thinking, etc., in solving a problem, the contents should be at a proper level for them. Based on these content selection principles, 12 themes were selected from 3 subjects to be taught offline, online and wireless web. The following table 1 details the themes.

Table 1. Unit-Specific Study Themes

\begin{tabular}{|c|c|c|c|}
\hline Subject & $\begin{array}{c}\text { Study } \\
\text { type }\end{array}$ & Unit title & Themes \\
\hline \multirow[t]{3}{*}{$\begin{array}{l}\text { Societ } \\
y\end{array}$} & Offline & $\begin{array}{l}\text { 1-1. Our life and } \\
\text { natural environment }\end{array}$ & $\begin{array}{l}\text { Study the characteristics of the } \\
\text { region where we live including } \\
\text { climate features and people's } \\
\text { lives. }\end{array}$ \\
\hline & Web & $\begin{array}{l}2-1 . \text { Life in urban } \\
\text { area }\end{array}$ & $\begin{array}{l}\text { Study the characteristics of the } \\
\text { region where we live and its } \\
\text { problems and solutions }\end{array}$ \\
\hline & $\begin{array}{l}\text { Wireles } \\
\text { s web }\end{array}$ & $\begin{array}{l}\text { 3-1. Natural disaster } \\
\text { and environmental } \\
\text { problem }\end{array}$ & $\begin{array}{l}\text { Study the types of natural disasters } \\
\text { in my town and efforts to prevent } \\
\text { them }\end{array}$ \\
\hline \multirow[t]{3}{*}{$\begin{array}{l}\text { Scienc } \\
\text { e }\end{array}$} & Offline & 1. Mirrors and lenses & $\begin{array}{l}\text { Study the characteristics of } \\
\text { convex/concave mirrors and lenses } \\
\text { and their application to daily } \\
\text { articles }\end{array}$ \\
\hline & Web & 4. Velocity of object & $\begin{array}{l}\text { Study how to calculate the } \\
\text { velocity of objects and calculate } \\
\text { diverse objects' velocity }\end{array}$ \\
\hline & $\begin{array}{l}\text { Wireles } \\
\text { s web }\end{array}$ & 5. Flowers & $\begin{array}{l}\text { Study the kinds of flowers and } \\
\text { compile a flower dictionary with } \\
\text { friendly flowers }\end{array}$ \\
\hline Subject & $\begin{array}{l}\text { Study } \\
\text { type }\end{array}$ & Unit title & Themes \\
\hline \multirow[t]{3}{*}{ Math } & Offline & 2. Pattern making & $\begin{array}{l}\text { Study articles having regular } \\
\text { patterns and find rules }\end{array}$ \\
\hline & Web & 4. Rectangular & $\begin{array}{l}\text { Find rectangulars in surrounding } \\
\text { environment and explore a sketch } \\
\text { and planar figure. }\end{array}$ \\
\hline & $\begin{array}{l}\text { Wireles } \\
\text { s web }\end{array}$ & $\begin{array}{l}\text { 6. Perimeter and area } \\
\text { of plane figures }\end{array}$ & $\begin{array}{l}\text { Find plane figures hidden in daily } \\
\text { environment and calculate their } \\
\text { perimeter and area }\end{array}$ \\
\hline $\begin{array}{l}\text { Practic } \\
\mathrm{e}\end{array}$ & Offline & 1. Our life at home & $\begin{array}{l}\text { Make PPT material to introduce } \\
\text { own family. }\end{array}$ \\
\hline
\end{tabular}




\begin{tabular}{|l|l|l|l|}
\hline Web & $\begin{array}{l}\text { 4. Clean living } \\
\text { environment }\end{array}$ & $\begin{array}{l}\text { Observe waste cleaning people in } \\
\text { every corner of the school. }\end{array}$ \\
\hline & $\begin{array}{l}\text { Wireles } \\
\text { s web }\end{array}$ & $\begin{array}{l}\text { 3. Raise flowers and } \\
\text { vegetables }\end{array}$ & $\begin{array}{l}\text { Study the characteristics of a plant } \\
\text { to raise and set a plan. }\end{array}$ \\
\hline
\end{tabular}

The themes selected above are separated by different units but, for this research experiment, they were performed in similar period. Each was taught in the form of class then the students were surveyed for their interest in and satisfaction with the class. Their final test results were referred to view their study achievement. The following figure is the graph of the students' class interest, satisfaction and subject-specific achievement.

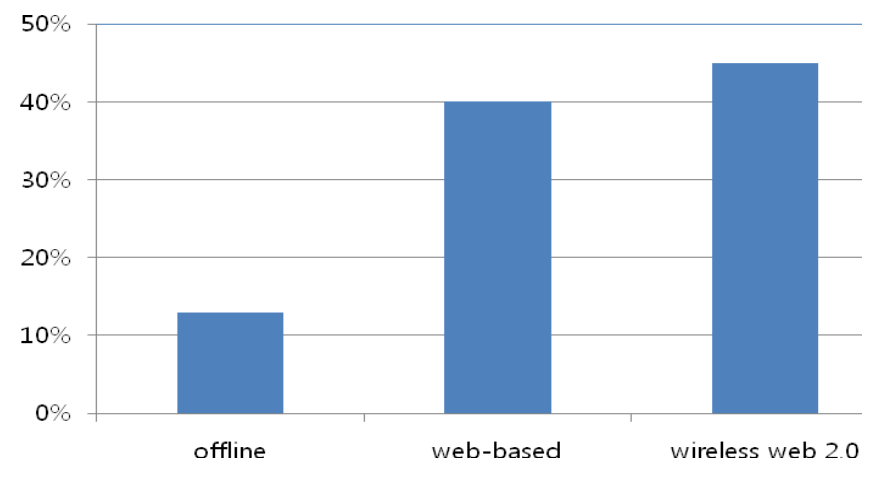

Figure 6. Students Interest According to Class Types

The students in this research were found to have $13.6 \%$ interest level in offline class; $40.4 \%$, web-based class; and $46 \%$, wireless web. This finding implies the effect of learning environment. The fact that they use a computer seems to work as a study motivation to show no big difference between web-based and wireless web activities. But as the wireless web was based on personal notebooks and reflected own thoughts or opinions in real time, it gained a higher score from the students.

In Figure 7, class satisfaction was $11.7 \%$ for offline study; $27.4 \%$ for web-based study; and $60.9 \%$ for wireless web study. The wireless web-based activities showed a relatively higher outcome. To look further into it, the students were found to be most satisfied with the process of discussing with friends in real time and amending/improving their colleagues' data by themselves. This finding indicates that mutual interaction especially valued by cooperative learning practices enhanced from the extant web-based practices.

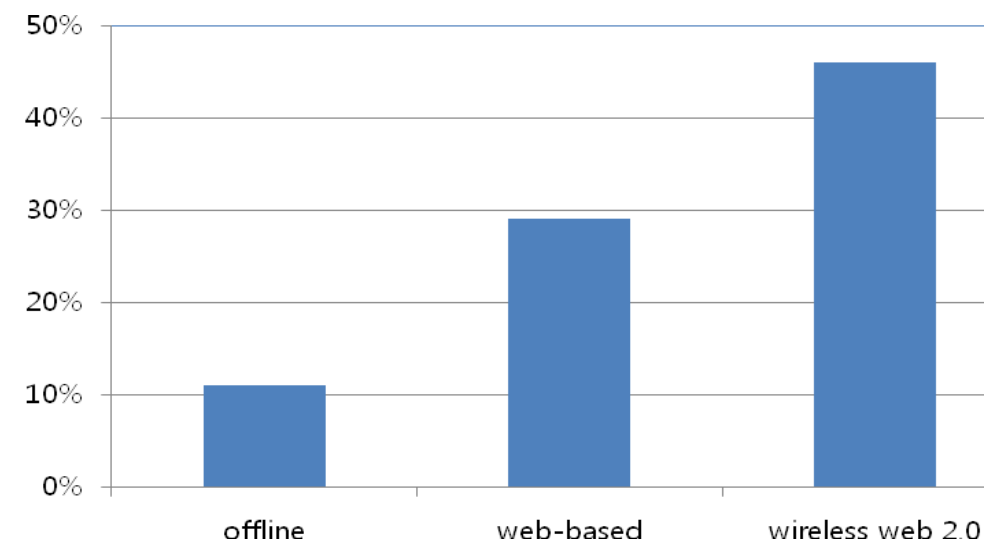

Figure 7. Satisfaction According to Class Types 


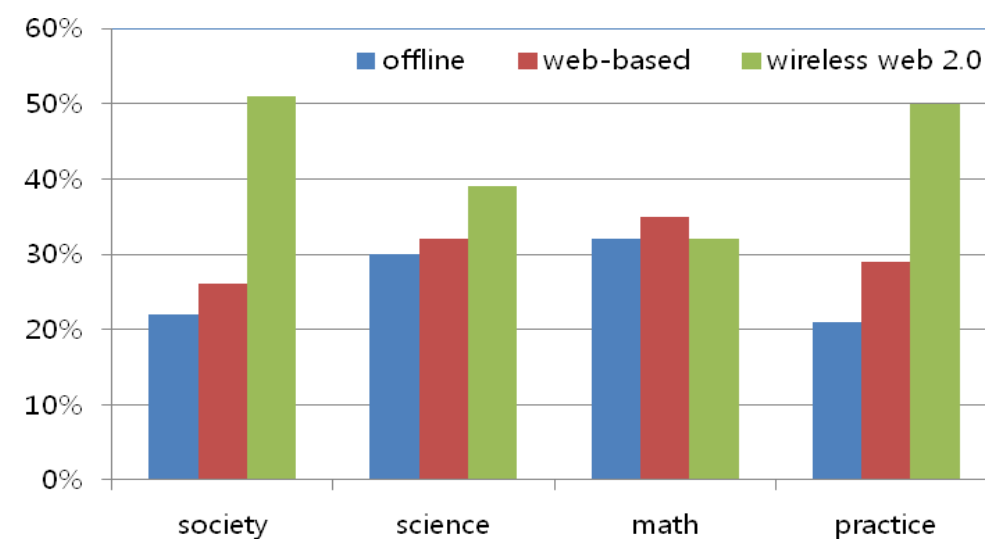

Figure 8. Subject-Specific Achievement

Concerning subject-specific student achievement, no remarkable difference is observed among the three different study types in science and math. As for math, rather web-based cooperative learning produced higher student achievement. Regarding society and practice, the wireless web-based learning was found to have far higher student achievement compared to offline and web-based types. It seems because in subjects such as science and math, the students already had significant performance gaps as some of them had studied such subject in advance for better performance. As for society and practice, the curriculums mainly deal with actual daily lives with many friendly themes so students' performance gaps were not wide.

\section{Conclusion}

In this research, web-based cooperative learning strategies were designed and applied in a wireless network environment with a view to address the shortfalls of the existing web-based cooperative learning practice. As a result, the following conclusions are made; first, wireless network environment helped ease the limitations in students' learning environment by reflecting their demand in real time so that the students could work as a main player of learning with full interest and proactive participation. Second, the introduction of web could address the problem of inefficient interaction among participants under the previous web-based cooperative learning because web enabled the students to share, process and re-produce their data. Third, as existing education curriculum was presented in relation to everyday issues, the suggested method could help improve the students' problem-solving ability as aimed by the cooperative learning practice.

In order to improve the effectiveness of this study, the following aspects need to be improved. Proper awareness of general teachers on web is necessary. And for efficient class performance, wireless network speed should be improved. In addition, regarding the application of the method to recently-interested digital textbooks, more study is needed on a comprehensive teaching-learning method in the era of $\mathrm{u}$ learning.

\section{Acknowledgements}

This research was supported by Basic Science Research Program through the National Research Foundation of Korea (NRF) funded by the Ministry of Education, Science Technology (NRF-2014R1A1A1008524). 


\section{References}

[1] X. Ochoa and E. Duval, "Towards automatic evaluation of learning object metadata quality", In Proceedings of the 2006 international conference on Advances in Conceptual Modeling: theory and practice", Berlin, Heidelberg, 372-381. (2006)

[2] X. Ochoa, J. Klerkx, B. Vandeputte and E. Duval, "On the use of learning object metadata: the GLOBE experience", Proceedings of the 6th European conference on Technology enhanced learning: towards ubiquitous learning”, Berlin, Heidelberg, 271-284. (2011)

[3] M.A. Sicilia, H. Ebner, S. Sanchez-Alonso, F. Alvarez, A. Abian, and E. Garcia-Barriocanal, "Navigating learning resources through linked data: A preliminary report on the re-design of Organic.Edunet", presented at the 1st International Workshop on eLearning Approaches for the Linked Data Age" (2011)

[4] E. Simperl, S. Wölger, S. Thaler, B. Norton, and T. Bürger, "Combining human and computation intelligence: the case of data interlinking tools", International Journal of Metadata and Semantic Ontologies, vol. 7”, no. 2,77-92. (2012)

[5] L. Dodds and I. Davis, "Linked Data Patterns: A pattern catalogue for modeling, publishing", and consuming Linked Data, Linked Data Patterns Pattern Cat. Model. Publ. Consum. Linked Data" (2010)

[6] T. Hoel, and J. Mason, "Expanding the Scope of Metadata and the Issue of Quality, in Proceedings of the 19th International Conference on Computers in Education", Chiang Mai, Thailand. (2011)

[7] M. Fernandez, M.d. Aquin and E. Motta, "Linking data across universities: an integrated video lectures dataset", in Proceedings of the 10th international conference on The semantic web Volume Part II", Berlin, Heidelberg, 49-64. (2011)

[8] M. Schmidt, R. de Virgilio, F. Giunchiglia, L. Tanca, T. Hornung, M. Meier, C. Pinkel and G. Lausen, "SP2Bench: A SPARQL Performance Benchmark", In Semantic Web Information Management", Eds. Springer Berlin Heidelberg, 371-393. (2010)

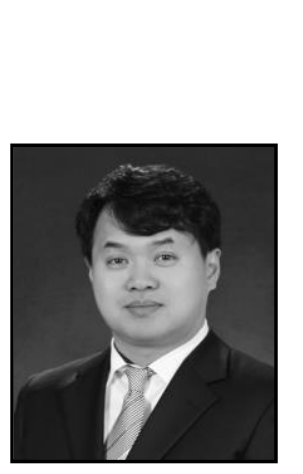

\section{Authors}

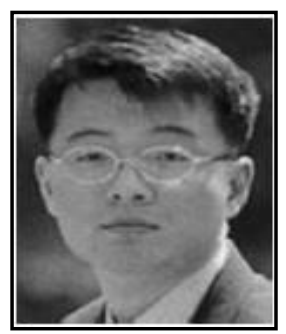

Kil Hong Joo, he received the M.S. and Ph.D. degree in Computer Science from Yonsei University, Seoul, Korea, in 2000 and 2004. He is currently a professor of Department of Computer Education at Gyeongin National University of Education, Korea. His current interests include mining data streams, data analysis and smart learning.

Nam Hun Park, he received the B.S., M.S. and Ph.D. degree in Computer Science from Yonsei University, Seoul, Korea, in 2000, 2002 and 2007. He was a post-Ph.D. at the Department of Computer Science, Worcester Polytech Institute, Worcester, MA. $\mathrm{He}$ is currently a professor of Department of Computer Science at Anyang University, Korea. His current interests include mining data streams. 
International Journal of Control and Automation Vol.8, No.10 (2015) 